\title{
Management of Pheochromocytoma in Pregnancy: Case Report and Review of the Literature
}

\author{
A. Reklou ${ }^{1, *}$, A. Kamparoudis ${ }^{2}$, A. Mamopoulos ${ }^{3}$, A. Lazaridis ${ }^{1}$, P. Rakitzi ${ }^{1}$, M. Grammatiki ${ }^{1}$, \\ M. Doumas ${ }^{1}$, E. Gkaliagkousi ${ }^{1}$, C. Spiridis ${ }^{2}$ and A. Karagiannis ${ }^{1}$ \\ ${ }^{1}$ 2nd Propedeutic Department of Internal Medicine, Aristotle University, Thessaloniki, Greece; ${ }^{2} 5^{\text {th }}$ Department of Sur- \\ gery, Aristotle University, Thessaloniki, Greece; ${ }^{3} 2^{\text {nd }}$ Depertment of Obstetrics Aristotle University, Thessaloniki, \\ Greece
}

\begin{abstract}
Pheochromocytoma during pregnancy is rare and lethal to the mother and fetus. Its diagnosis is often missed during pregnancy and is usually made during labour or immediately postpartum with increased mortality rates for both the mother and fetus. Early diagnosis and timely, appropriate management reduce possible maternal and fetal complications. A case of pheochromocytoma recognized at early pregnancy is described.
\end{abstract}

Keywords: Pheochromocytoma, hypertensive crisis, pregnancy, maternal mortality, fetal mortality.

\section{INTRODUCTION}

Pheochromocytoma is a neuroendocrine tumor arising from chromaffin cells of the adrenal medulla or the sympathetic ganglia. Its presence is usually suspected in hypertensive patients with the appearance of symptoms such as headache, sweating or palpitations. Although it is an unusual cause of hypertension accounting for about $0.2-0.4 \%$ of cases, it may lead to severe and potentially lethal hypertensive crises due to the effects of the released catecholamines $[1,2]$. During pregnancy pheochromocytoma occurs with a frequency of $0.002 \%$ of all pregnancies [3,4]. Confusion with the much more prevalent forms of pregnancy-related hypertension is the main cause of overlooking the diagnosis. Consequently, a timely diagnosis and proper treatment are crucial because they may improve maternal and fetal morbidity and mortality [5-8]. If it remains undiagnosed the maternal and fetal mortality are estimated at around $50 \%$, whereas the timely diagnosis improves the rates to $<5 \%$ and $<15 \%$ respectively $[9,10]$. We report a pregnant woman with pheochromocytoma which was diagnosed at the ninth week of gestation. Additionally, we analyze both the importance of early diagnosis and proper treatment for a successful outcome to take place.

\section{CASE REPORT}

A 34-year-old woman was admitted to our department at 9 weeks gestation for management of hypertension. A history of paroxysmal episodes of hypertensive crises accompanied with headaches, sweating and palpitations was present from 8 months. Actually, in three episodes she was severely hypertensive with a blood pressure (BP) of 240/140 $\mathrm{mmHg}$. Her previous medical history raised the suspicion of

*Address correspondence to this author at the Department of Internal Medicine, Aristotle University, Konstantinoupoleos 49 str., Thessaloniki, 546 42, Greece; Tel: +302310 892078; Fax: +302310 835955;

E-mail: machirk128@yahoo.com pheochromocytoma; therefore, imaging and biochemical testing was performed to confirm or exclude the diagnosis. Ultrasound and magnetic resonance imaging demonstrated a 7,5 $\mathrm{cm}$ x 9,2 cm right adrenal mass (Fig. 1, 2).

Specialized biochemical examinations revealed increase in urinary catecholamines $(889 \mathrm{mg} / 24 \mathrm{~h}$; reference values: $<150 \mathrm{mg} / 24 \mathrm{~h})$ and urinary vanillymandelic acid $(28 \mathrm{mg} / 24 \mathrm{~h}$; reference values: $1.8-6.7 \mathrm{mg} / 24 \mathrm{~h}$ ), which confirmed the diagnosis of pheochromocytoma.

The patient was initially treated with alpha-blockers (terazosin) with a gradual increase in dose up to $5 \mathrm{mg}$ two times per day. Subsequently $\beta$-blockers (atenolol $25 \mathrm{mg}$ once daily) were added to the treatment 3 days later to account for tachycardia. This combination therapy was appropriate for the preoperative medical preparation so as to block the effects of released catecholamines. A multidisciplinary team of hypertension specialists, surgeons, anesthesiologists, pediatricians and obstetricians decided to perform tumor excision at the 13th week of gestation, in order to protect the fetus organogenesis and allow for proper preoperative management. The patient received the medication at home until the $13^{\text {th }}$ week of gestation with a maximal pre-surgical BP of $<130 / 80 \mathrm{mmHg}$ and complete disappearance of clinical manifestations. The surgery was conducted without any complications for the mother and fetus. BP remained remarkably stable during operation (even during tumor excision) due to proper preoperative management and the experience of the anesthesiology team. Figs. (3 and 4) depict the excised tumor, which had all the macroscopic features of pheochromocytoma with the characteristic color and within tumor hemorrhagic lesions and fusions.

The histological examination confirmed the preoperative diagnosis of pheochromocytoma. Postoperatively, the patient was in excellent clinical condition with a normal BP. The obstetrician confirmed the normal development of the fetus. The new sample of urinary catecholamines was within 


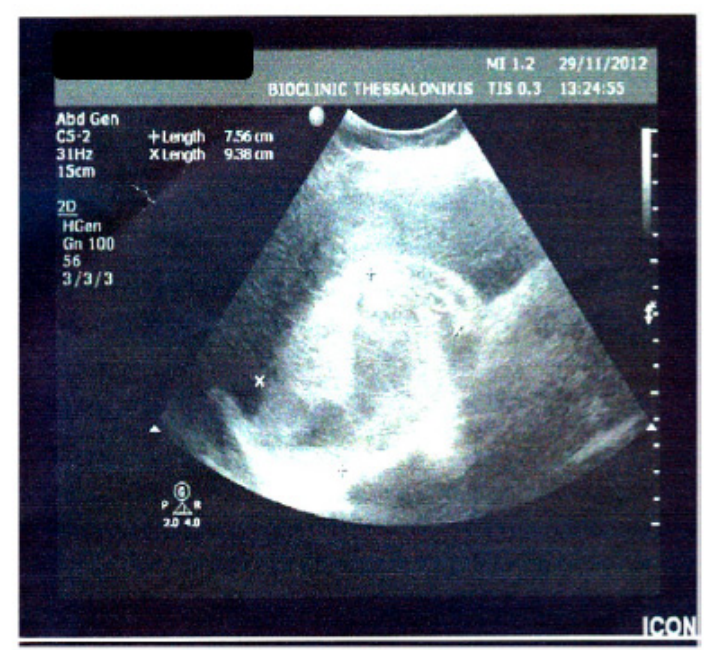

Fig. (1). Ultrasound of the right adrenal showing a large mass.

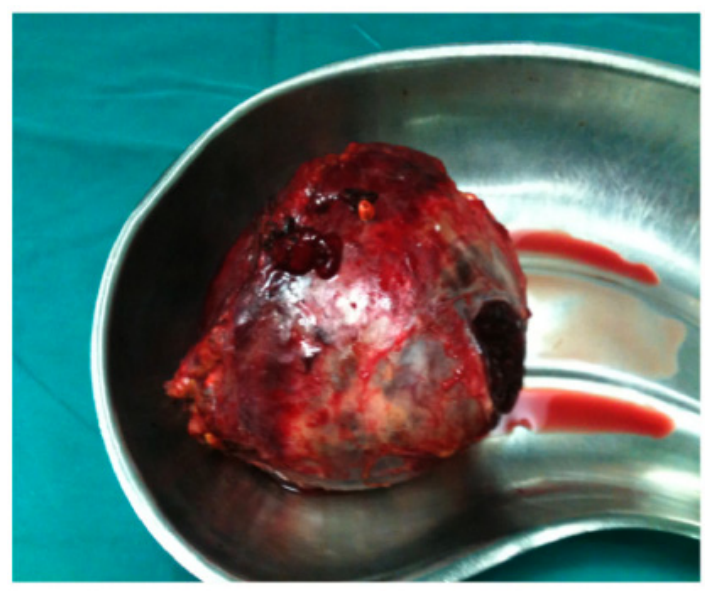

Fig. (3). Photo depicting the mass right after surgical excision.

reference values. The patient was discharged five days after the operation. Six months later (at the $39^{\text {th }}$ week of gestation) a healthy infant was born with vaginal delivery.

\section{DISCUSSION}

This case illustrates that the timely antenatal diagnosis of pheochromocytoma along with a proper preoperative adrenergic blockade and an experienced multi-specialist team result in the successful management of this highly risky clinical condition. The key factor of the successful management is the early detection of the tumor during pregnancy and its appropriate treatment $[11,12]$. Diagnosis in the antenatal period and resection during pregnancy were combined with better outcomes compared with the diagnosis in the immediate postnatal period or during delivery [13]. On the other hand, when the detection of the tumor was made before 23 weeks' gestation, slightly more successful results were observed with the excision in the second trimester than in the third trimester, but without statistical significance [13].

In the case of antenatal diagnosis the resection is recommended to be undertaken with laparoscopic procedures com-

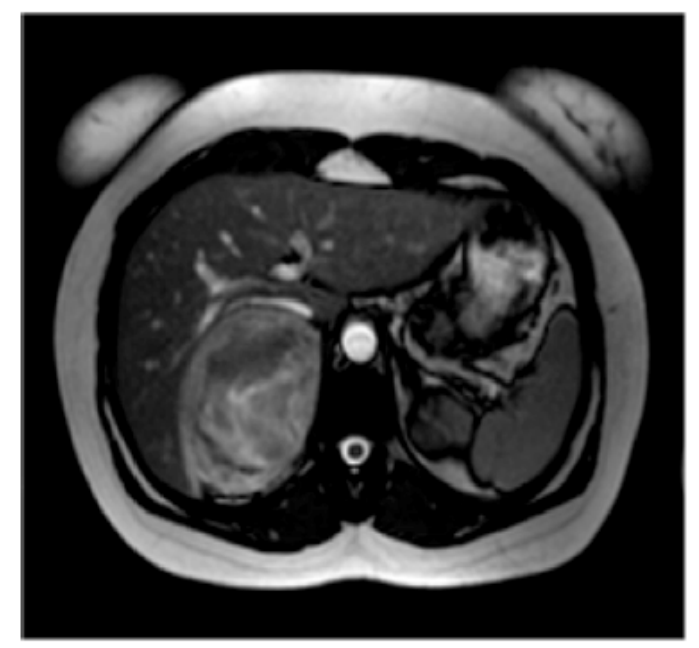

Fig. (2). Abdominal magnetic resonance imaging revealing a large mass originating from the right adrenal gland.

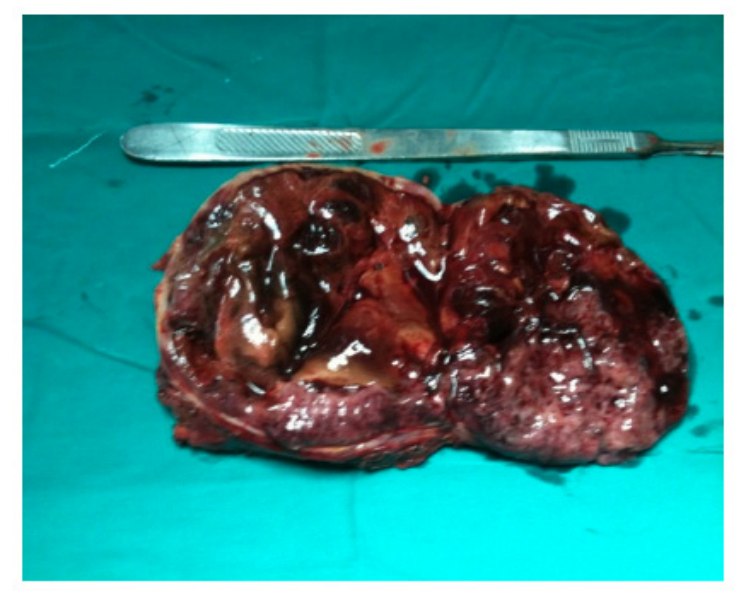

Fig. (4). Characteristic features of pheochromocytoma in the tumour.

pared to the conventional open surgery. With laparoscopic surgery better outcomes are achieved because of the timely control of catecholamine release and therefore hemodynamic stability and safety $[14,15]$.

Caesarean section with epidural, general or combined anesthesia is the recommended mode of delivery and is related with lower maternal mortality $(19 \%)$ than vaginal delivery $(31 \%)[6,15,16]$. When the tumor is removed before 24 weeks of gestation, delivery can be conducted either way.

In conclusion, timely diagnosis of pheochromocytoma in a pregnant hypertensive patient and appropriate medical preoperative management followed by subsequent laparoscopic resection during pregnancy lead to reduction of maternal and fetal mortality. Most successful outcomes can be achieved with the contribution of a multidisciplinary team with highlevel expertise in this specific field.

\section{CONFLICT OF INTEREST}

The author(s) confirm that this article content has no conflicts of interest. 


\section{ACKNOWLEDGEMENT}

We wish to thank our gratitude to the anesthesiology (Prof. Anagnostara) and the pediatric team (Prof. Kollios and Dr Kougia) of the Hospital for their valuable help regarding patient's management.

\section{REFERENCES}

[1] Anagnostis P, Karagiannis A, Tziomalos K, Athyros VG, Kita M, Mikhailidis DP. Endocrine hypertension: diagnosis and management of a complex clinical entity. Curr Vasc Pharmacol 2010; 8: 646-60.

[2] Karagiannis A, Mikhailidis DP, Athyros VG, Harsoulis F. Pheochromocytoma: an update on genetics and management. Endocr Relat Cancer 2007; 14: 935-56.

[3] Harper MA, Murnaghan GA, Kennedy L, et al. Phaeochromocytoma in pregnancy. Five cases and a review of the literature. $\mathrm{Br} \mathrm{J}$ Obstet Gynaecol 1989; 96: 594-606.

[4] Harrington JL, Farley DR, van Heerden JA, Ramin KD. Adrenal tumors and pregnancy. World J Surg 1999; 23: 182-6.

[5] Ahlawat SK, Jain S, Kumari S, et al. Phaeochromocytoma associated with pregnancy: case report and review of the literature. Obstet Gynecol Surv 1999; 54: 728-37.

[6] Schenker JG, Granat M. Phaeochromocytoma and pregnancy -an updated appraisal. Aust N Z J Obstet Gynaecol 1982; 22: 1-10.
[7] Oishi S, Sato T. Phaeochromocytoma in pregnancy: a review of the Japanese literature. Endocr J 1994; 41: 219-25.

[8] Sarathi V, Lila AR, Bandgar TR, et al. Phaeochromocytoma and pregnancy: a rare but dangerous combination. Endocr Pract 2010, 16: 300-9.

[9] Schenker JG, Chowers I. Phaeochromocytoma and pregnancy. Review of 89 cases. Obstet Gynecol Surv 1971; 26: 739-47.

[10] Dean RE. Phaeochromocytoma and pregnancy. Obstet Gynecol 1958; 11: 35-42.

[11] Grossman A, Pacak K, Sawka A, et al. Biochemical diagnosis and localization of phaeochromocytoma: can we reach a consensus? Ann N Y Acad Sci 2006; 1073: 332-47.

[12] Ilias I, Sahdev A, Reznek RH, et al. The optimal imaging of adrenal tumours: a comparison of different methods. Endocr Relat Cancer 2007; 14: 587-99.

[13] Biggar MA, Lennard TWJ. Systematic review of phaeochromocytoma in pregnancy. Br J Surg 2013; 100: 182-90.

[14] Fernaandez-Cruz L, Taura P, Saenz A, et al. Laparoscopic approach to pheochromocytoma hemodynamic changes and catecholamine secretion. World J Surg 1996; 20: 762-8.

[15] Amar L, Servais A, Gimenez-Roqueplo AP, et al. Year of diagnosis, features at presentation, and risk of recurrence in patients with phaeochromocytoma or secreting paraganglioma. J Clin Endocrinol Metab 2005; 90: 2110-6.

[16] Lenders JW. Pheochromocytoma and pregnancy: a deceptive connection. Eur J Endocrinol 2012; 166: 143-50.

(C) Reklou et al.; Licensee Bentham Open.

This is an open access article licensed under the terms of the Creative Commons Attribution Non-Commercial License (http://creativecommons.org/licenses/by-nc/3.0/) which permits unrestricted, non-commercial use, distribution and reproduction in any medium, provided the work is properly cited. 